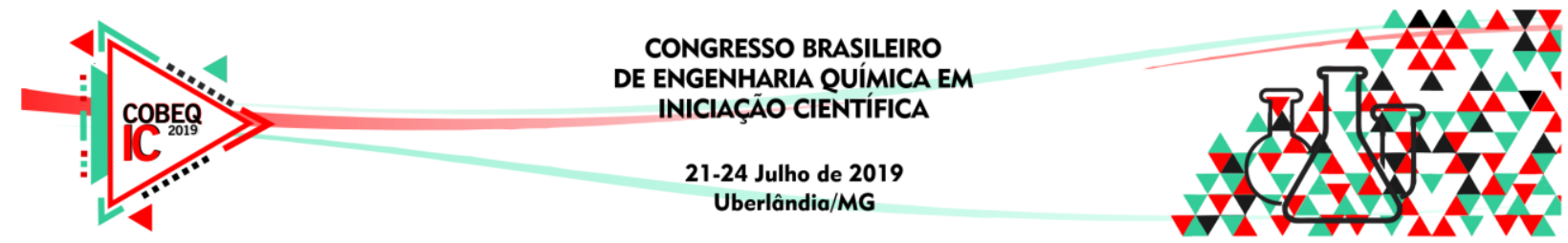

\title{
ESTUDO EXPERIMENTAL DE PIRÓLISE LENTA DE PELLETS DE CASCA DE CAFÉ EM UM REATOR DE LEITO FIXO
}

\author{
F. A. BORGES ${ }^{1}$, K. L. S. $\operatorname{COSTA}^{1}$ e T. J. P. OLIVEIRA ${ }^{2}$ \\ ${ }^{1}$ Universidade Federal de Lavras, Faculdade de Engenharia Química \\ ${ }^{2}$ Universidade Federal de Lavras Departamento de Engenharia \\ E-mail para contato: fabianaab@estudante.ufla.br
}

\begin{abstract}
RESUMO - Os estudos da biomassa e seus resíduos apresentam um grande potencial para utilização na indústria química, tornando-se uma alternativa para os combustíveis fósseis e contribuindo para o desenvolvimento sustentável. Assim, esse trabalho teve como objetivo avaliar o efeito da temperatura de reação sobre os rendimentos dos produtos, caracterizar as frações líquida resultantes do processo pirolítico e analisar o bio-óleo obtido em um reator de leito fixo, com o intuito de identificar as potencialidades deste resíduo na produção de energia. As temperaturas estudadas na pirólise lenta dos pellets da casca de café foram de 400, 450 e $500{ }^{\circ} \mathrm{C}$. Com base nas análises dos cromatogramas verifica-se que não houve diferença entre principais compostos encontrados, com a variação de temperatura da pirólise, existindo apenas uma variabilidade de intensidade relativa de cada composto em sua temperatura. Os principais compostos identificados nas temperaturas estudadas foram os fenólicos: fenol, 2-metilfenol (O-cresol), 3metilfenol (M-cresol) e também naftaleno, a cafeína e o ácido adípico bis(etilhexil) éster, também conhecido como adipol 2EH. Desta forma, o processo de pirólise dos pellets da casca de café apresenta potencialidades para o aproveitamento energético e a obtenção de compostos químicos de valor agregado e reduzindo o impacto ambiental causado pela disposição inadequada de materiais lignocelulósicos.
\end{abstract}

\section{INTRODUÇÃO}

O desenvolvimento econômico e o crescimento populacional observado nas últimas décadas, causaram um aumento na demanda de energia, essa desigualdade entre o aumento da demanda e a escassez de energia será um desafio global no futuro próximo. Nesse contexto, aparecem os biocombustíveis, combustíveis derivados de biomassa renovável, que apresentam um potencial para reduzir a dependência do uso de combustíveis fósseis, além de abordar questões de segurança na relação combustíveis e meio ambiente, favorecem benefícios socioeconômicos, tais como o desenvolvimento sustentável e a geração de empregos (Sanna, 2014). 


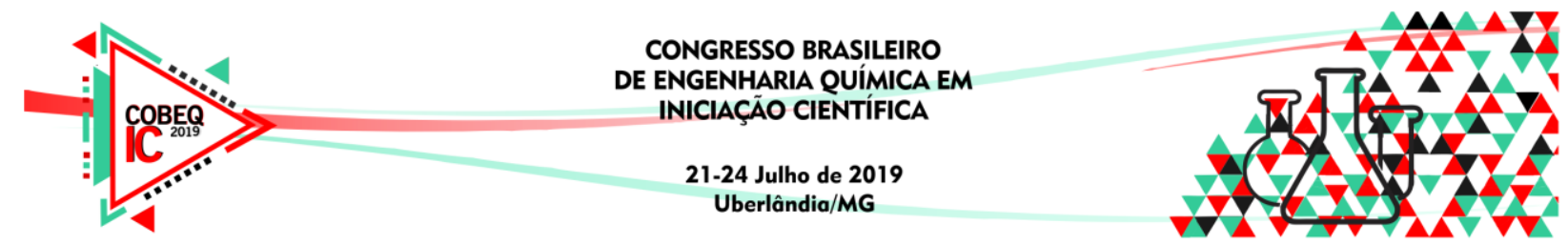

O Brasil é conhecido por sua grande capacidade de produção, que é muitas vezes refletida na exportação de commodities agrícolas, gerando assim, biomassa. A biomassa gerada deve ser considerada como uma oportunidade e base para conhecimentos técnicocientíficos nacionais e de redução de impactos ambientais (Vaz Júnior, 2011). Como um dos principais commodities pode-se citar o café, sendo que o país se destaca como maior produtor e exportador do mundo, representado mais de $35 \%$ da produção mundial total nos últimos 5 anos, alcançando cerca de 267,8 milhões de sacas de $60 \mathrm{~kg}$. Durante o seu processamento muitos subprodutos são gerados e descartados após a retirada do grão, sendo as cascas do café, os principais resíduos sólidos do processamento, dado que para cada $1 \mathrm{~kg}$ de café produzido são gerados cerca de $1 \mathrm{~kg}$ de casca (Gouvea et al., 2009).

O principal problema do uso da biomassa como matéria prima para a geração de energia é a baixa densidade que possui, fator que encarece sua utilização e dificulta seu transporte (Rennard et al., 2010). Uma maneira interessante para a utilização desta matéria prima é densifica-la, transformando-as em pellets, aumentando sua massa por unidade de volume (Salema et al., 2017), o que facilita o armazenamento e o transporte, além de melhorar o comportamento físico e de combustão, permitindo até a utilização de uma maior variedade de materiais lignocelulósicos como combustíveis (Tabares et al. 2000).

Diante dos entraves para a transformação da biomassa em bioenergia útil, muitos estudos de conversão da mesma foram desenvolvidos nos últimos anos segundo Guedes (2010), as principais rotas de conversão da biomassa são combustão, liquefação, fermentação, biodigestão, gaseifcação e pirólise.

A pirólise pode ser definida como a decomposição térmica de material orgânico na ausência total ou parcial de um agente oxidante ou em uma atmosfera onde a concentração de oxigênio impeça a combustão. Ela se destaca por gerar produtos com valores agregados que podem ser usados como fontes de combustíveis, sendo eles líquidos, sólidos e/ou gasosos (Pedroza, 2011).

O líquido resultante da pirólise, conhecido como bio-óleo, é um combustível líquido renovável, o que lhe oferece vantagem sobre os derivados do petróleo, além de poder ser usado para a produção de várias substâncias químicas (Guedes et al., 2010). O resíduo sólido apresenta uma estrutura poros rica em carbono, similar ao carvão fóssil, é um produto útil que pode ser usado como biocombustível (Pehlivan et al., 2017) ou incorporado no solo, o qual denomina-se biochar, melhorando sua fertilidade (De Voorde et al. 2014). Já a fração gasosa pode ser queimada para geração de calor/energia (Bridgwater, 2012).

Com o propósito de unir os processos de pirólise e densificação da biomassa, a fim de difundir a utilização dela como biocombustível, através do uso da casca de café, uma biomassa residual amplamente encontrada no Brasil que, tem seus usos e aplicações rentáveis pouco pesquisados, este estudo é realizado.

De modo geral o presente trabalho tem-se por objetivo estudar alternativas para a destinação desses resíduos agroindustriais, focando na produção de pellets e posterior pirólise, visando a obtenção de um bio-óleo de qualidade para fornecimento de biocombustíveis ou produtos químicos de valor agregado. 


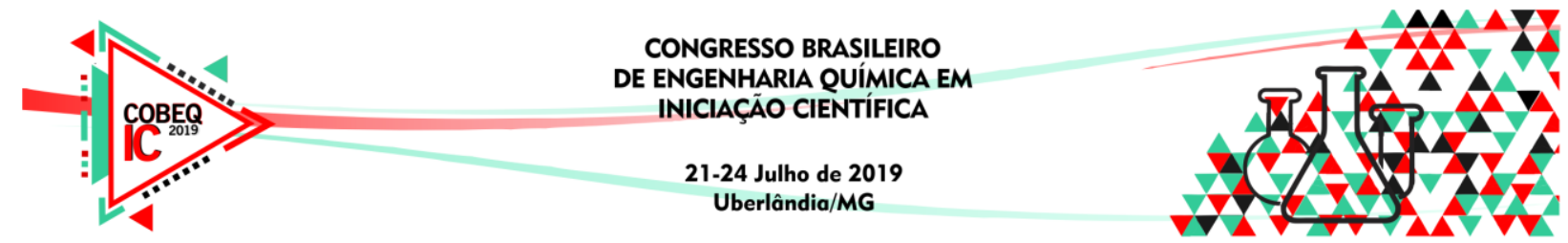

\section{MATERIAL E MÉTODOS}

\subsection{Processamento dos Pellets}

Foram moídos $50 \mathrm{~kg}$ de casca de café (in natura) com o objetivo de diminuir o tamanho das partículas. Posteriormente, o material passante pela peneira com granulometria menor a $1,2 \mathrm{~mm}$ (terceira granulometria) foi utilizado para a produção dos pellets de $7,10 \mathrm{~mm}$ de diâmetro e $16,29 \mathrm{~mm}$ de comprimento com $250 \mathrm{~kg} / \mathrm{cm}^{2}$ de pressão na pelletizadora marca Lippel.

\subsection{Obtenção do bio-óleo}

Primeiramente, os pellets foram previamente secos em estufa a $105^{\circ} \mathrm{C}$ por aproximadamente 24 horas. O processo foi realizado num forno tipo mufla, onde cerca de $200 \mathrm{~g}$ de pellets foram inseridos em uma cápsula de inox que, em seguida, foi acoplada na parte superior do forno, onde há uma tubulação para possibilitar a saída dos gases. Por meio de um controle de temperatura os parâmetros operacionais requeridos foram préestabelecidos. $\mathrm{O}$ experimento baseou-se em três temperaturas finais de pirólise, $400^{\circ} \mathrm{C}, 450^{\circ} \mathrm{C}$ e $500^{\circ} \mathrm{C}$. O tempo de residência em cada temperatura final foi de 1 hora. O bio-óleo recuperado em cada experimento foi coletado durante todo o processo e armazenado em frascos de vidros.

\subsection{Caracterização do bio-óleo}

Os compostos presentes no bio-óleo foram identificados por cromatografia gasosa acoplada ao espectrômetro de massas (GC/MS) do tipo quadrupolo, modelo 7890A/5975C (Agilent) em triplicata. A coluna utilizada para as análises foi HP-5MS (30 m x 0,25 mm x $0,25 \mu \mathrm{m})$ e gás de arraste He $(99,999)$ com fluxo de $1,56 \mathrm{~mL}$ min-1. A temperatura do injetor foi mantida a $300^{\circ} \mathrm{C}$. A razão split foi de $10: 1$. A temperatura inicial do forno foi mantida a $40^{\circ} \mathrm{C}$, seguida de uma rampa de aquecimento de $5^{\circ} \mathrm{C}$ min- 1 até $250^{\circ} \mathrm{C}$, onde permaneceu por 10 minutos. Os compostos presentes no bio-óleo foram identificados por meio da biblioteca NIST versão 2.0 com índice de similaridade maior que $60 \%$. Antes das análises, os compostos presentes no bio-óleo foram extraídos utilizando clorofórmio. A fase do clorofórmio foi retirada utilizando uma seringa de vidro. As amostras foram filtradas com filtro de seringa PTFE hidrofóbico antes de serem transferidas para o vial. As análises de GC/MS foram realizadas no Laboratório de Gestão de Resíduos Químicos da Universidade Federal de Lavras.

\section{RESULTADOS E DISCUSSÕES}

Os resultados obtidos a partir da análise da fase orgânica do bio-óleo resultante da pirólise dos pellets de casca café, no GC/MS, nas temperaturas de $400^{\circ}, 450^{\circ}$ e $500{ }^{\circ} \mathrm{C}$ são apresentados na Figura 1- A, B e C respectivamente, estando os compostos dos picos de maior intensidade, devidamente identificados. 


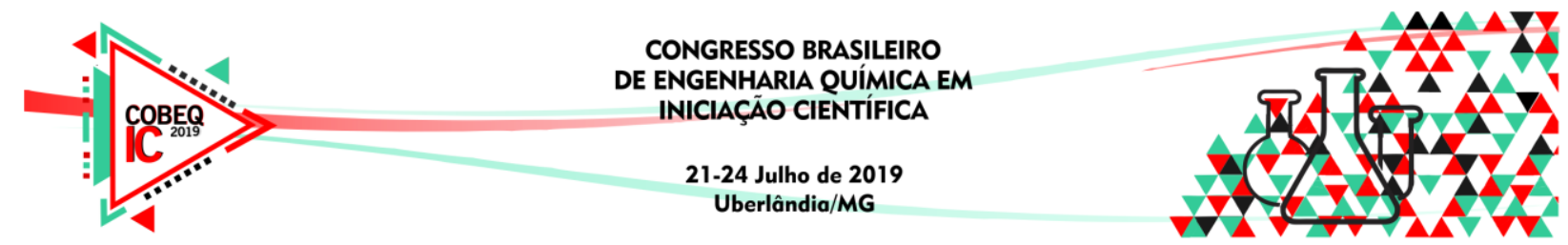

Figura 1 - Cromatograma do bio-óleo da pirólise de pellets de casca de café a $400{ }^{\circ} \mathrm{C}(\mathrm{A})$, $450{ }^{\circ} \mathrm{C}(\mathrm{B}), 500{ }^{\circ} \mathrm{C}(\mathrm{C})$ : Identificação dos picos e tempo de retenção.
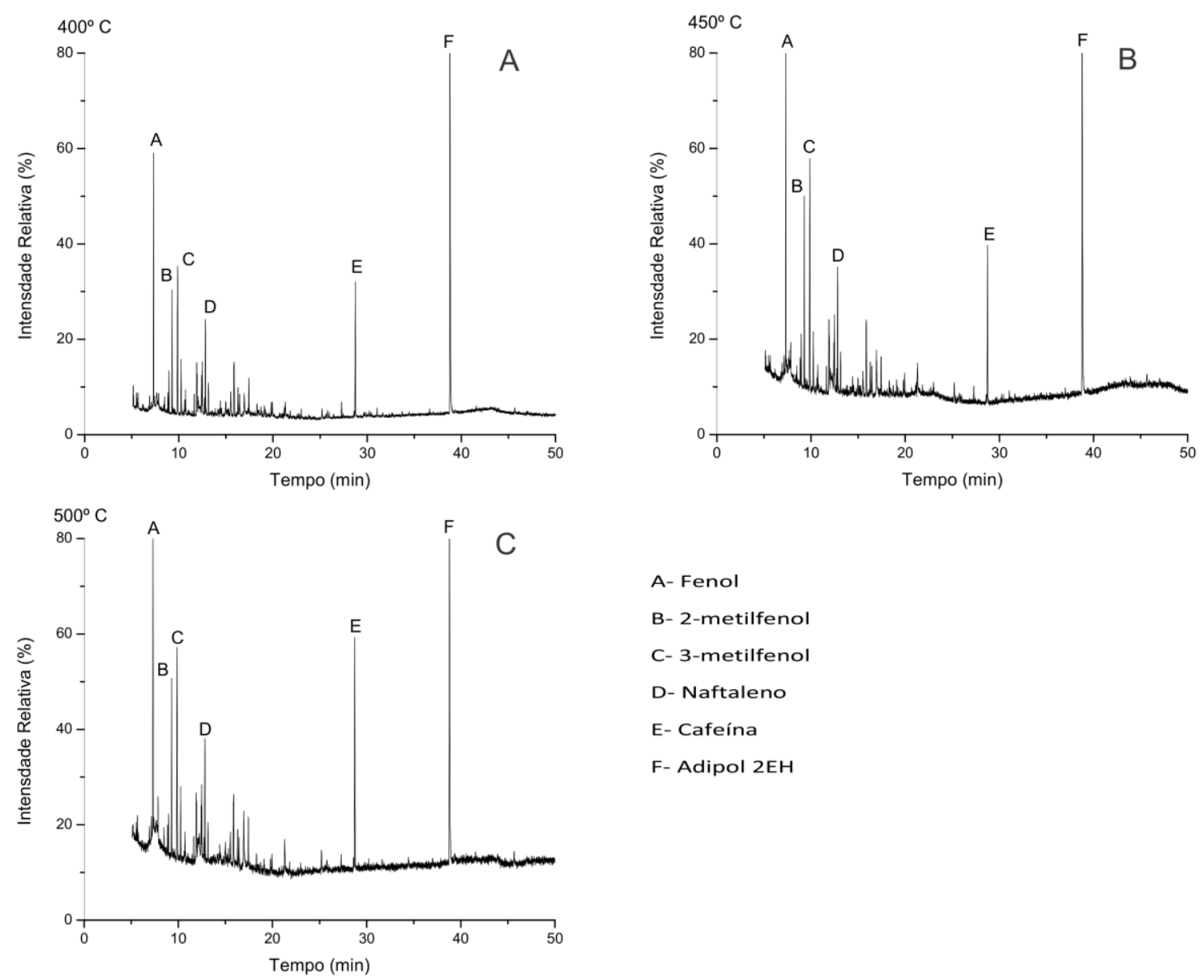
A- Fenol
B- 2-metilfenol
C- 3-metilfenol
D- Naftaleno
E- Cafeína
F- Adipol 2EH

Pela análise dos cromatogramas apresentados, é possível perceber que não houve diferença entre principais compostos encontrados, com a variação de temperatura da pirólise, existindo apenas uma variabilidade de intensidade relativa de cada composto em sua temperatura.

Detectou-se uma variabilidade de compostos presentes nas amostras de bio-óleo orgânico, sendo que, dentre esses, os principais foram os compostos fenólicos: fenol, 2metilfenol (O-cresol), 3-metilfenol (M-cresol) e também naftaleno, a cafeína e o ácido adípico bis(etilhexil) éster, também conhecido como adipol 2EH.

Em uma análise mais sistêmica para utilização dos compostos encontrados no bio-óleo, pode-se citar a ampla utilização dos compostos fenólicos na indústria química, como na síntese de resinas e medicamentos (Effendi et al., 2008).

Nos dias atuais o custo do fenol e sua disponibilidade, estão diretamente ligados ao preço do petróleo, pois ele é a principal fonte para obtenção dos fenóis utilizados pelas indústrias, sendo tais produtos que utilizam fenol relativamente caros (Oliveira, 2015), tendo 


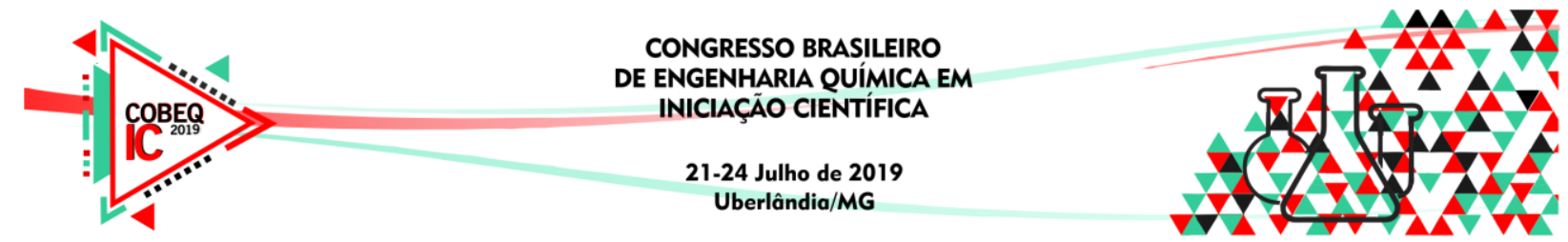

em vista tais fatores, a busca por outras fontes para obtenção do fenol se mostram bastante promissoras, uma proposta que já vem sendo feita é a de se utilizar resinas fenólicas obtidas a partir de materiais lignocelulósicos (Effendi et al., 2008).

O naftaleno é um hidrocarboneto aromático que pode ser obtido através do alcatrão e é importante matéria prima para repelentes e pesticidas, bem como polímeros e resinas sintéticas (Cardoso, 2016). Ainda não se tem estudos sobre a utilização de fontes como o bioóleo para a obtenção do naftaleno.

A cafeína, um alcaloide encontrado em certas plantas e amplamente utilizada para consumo como estimulante. A presença de piscos intensos se dá em recorrência da matéria prima da pirólise, os pellets de casca de café.

Altos níveis de cafeína são encontrados no solo na terra com mudas e grãos de café. Estudos propõem que a cafeína tem função natural como uma espécie de pesticida e inibidor da germinação de sementes de outras mudas nas proximidades, a fim de garantir maiores chances de sobrevivência (Baumann,1984).

Já o adipol 2EH é amplamente utilizado como plastificante, para produção de produtos flexíveis de policloreto de vinila, geralmente para filmes de alimentos, bem como outros plásticos (Rahman, 2009).

\section{CONCLUSÕES}

A partir das análises cromatográficas para o bio-óleo obtido a partir da pirólise de pellets de casca de café obtido de diferentes temperaturas, foi possível observar que nas 3 temperaturas utilizadas obteve-se os mesmos compostos principais sendo eles fenol, 2metilfenol, 3-metilfenol, naftaleno, cafeína e o adipol 2EH.

Cada um desses compostos pode ser utilizado de uma maneira específica na indústria química, sendo suas fontes principais variadas, entretanto o estudo do bio-óleo como possível fonte de tais compostos apresenta-se promissor.

\section{AGRADECIMENTOS}

Os autores agradecem à FAPEMIG, CNPq e CAPES pelo apoio financeiro.

\section{REFERÊNCIAS}

BAUMANN, T. W. Metabolism and excretion of caffeine during germination of Coffea arabica. Plant and Cell Physiology, v.25, p.1431-6, 1984.

BRIDGWATER, A. V. Review of fast pyrolysis of biomass and product upgrading. Biomass and Bioenergy, v. 38, p. 68-94, 2012

CARDoso, M.G., PUGGINA, M. F. Química Orgânica- Conceitos e Reações. Lavras. Editora Ufla, 2016. 


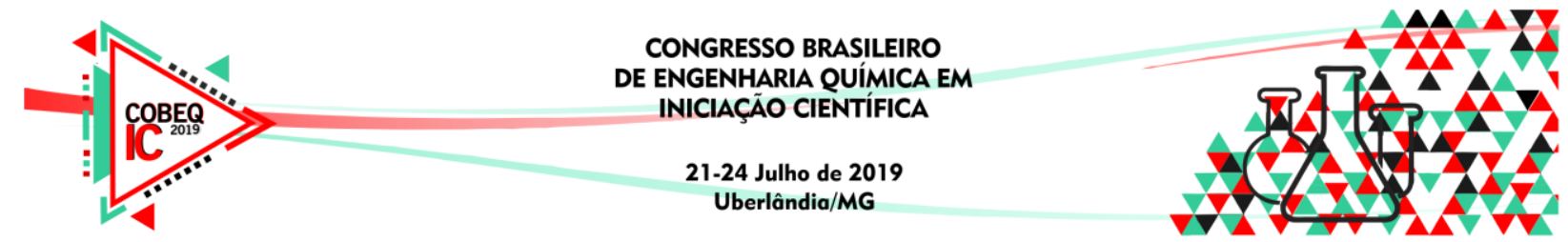

DE VOORDE, T. F. J. VAN et al. Soil biochar amendment in a nature restoration area: effects on plant productivity and community composition. Ecological Applications, v. 24, p. 1167-1177, 2014.

EFFENDI, A; GERHAUSER, H.; BRIDGWATER, A. V. Production of renewable phenolic resins by thermochemical conversion of biomass: A review. Renewable and Sustainable Energy Reviews, v.12, p 2092-2116, 2008.

GOUVEA, B. M. et al. Feasibility of ethanol production from coffee husks. Biotechnology Letters, v. 31, n. 9, p. 1315-1319, 2009.

GUEDES, C. L. B. et al. Avaliação de biocombustível derivado do bio-óleo obtido por pirólise rápida de biomassa lignocelulósica como aditivo para gasolina. Química Nova, São Paulo,v. 33, n. 4, p. 781-786, 2010.

OLIVEIRA, T. J. P. Pirólise rápida de casca de soja: desenvolvimento do reator de leito fluidizado, análise do Bio-óleo produzido e do vapor obtido na pirólise analítica. Dissertação- UFU. Uberlândia, 2015.

PEDROZA, M. M., et al. Balanço energético da pirólise de lodo de esgoto: uma abordagem das propriedades termodinâmicas do processo. Congresso Brasileiro de Engenharia Química, 18., Foz do Iguaçu: Anais. Foz do Iguaçu. ABEP, p.8 2010.

PEHLIVAN, E. et al. Production and characterization of chars from cherry pulp via pyrolysis. Journal of Environmental Management, v. 203, p. 1017-1025, dez. 2017.

RAHMAN, A.B., CHAIBAKHSH, N., BASRI, M. Appl Biochem Biotechnol, 2009.

RENNARD, D.; FRESH, F.; CZERNIK, S.; JOSEPSHON, T. Production of synthesis gas by partial oxidation and steam reforming as biomass pyrolysis oils. International Journal of Hidrogen Energy, v.35, p 4048-4059, 2010.

SAlEMA, A. A.; AFZAL, M. T.; BENNAMOUN, L. Pyrolysis of corn stalk biomass briquettes in a scaled-up microwave technology. Bioresource Technology, v. 233, p. 353-362, 2017.

SANNA, A. Advanced Biofuels from Thermochemical Processing of Sustainable Biomass in Europe. BioEnergy Research, p. 36-47, 2014.

TABARES, J. L. M. et al. Feasibility study of energy use for densificated lignocellulosic material (briquettes). p. 9, 2000.

VAZ JÚNIOR, S. Biorrefnarias: cenários e perspectivas. Brasília: Athalaia, 2011 